\title{
NOU 2014:10 - Proposal for New Rules Regarding Criminal Insanity and Related Issues, Norway post-22 July
}

\author{
LINDA GRÖNING AND GEORG FREDRIK RIEBER-MOHN *
}

\section{The proposal's background}

The criminal case in the aftermath of the terrorist attack in the centre of Oslo and on Utøya on 22 July 2011 raised a wide-ranging discussion on the way Norwegian criminal law tackles offenders with mental disorders. The discussion conducted in the public debate concerned particularly the configuration of rules on criminal insanity, the role of experts in criminal justice and the need for particular sanctions for criminally insane ${ }^{1}$ offenders.

The backdrop for this debate was to a large extent the fact that Norwegian criminal law uses a 'medical model' for the definition of criminal insanity. Under section 44 of the Criminal Code, a defendant that is psychotic at the time of the offence is absolved from criminal responsibility. This provision essentially 'equates' criminal insanity with psychosis, and does not operate with any criteria requiring causality, or any other additional ('psychological') criteria as is the case in many countries. It has been questioned - particularly after the 22 July case - whether the medical model gives an erroneous delimitation of who should be absolved from criminal responsibility. It has also been questioned whether the experts (most often psychiatrists) have too much power in the determination of whether a defendant is criminally insane.

Linda Gröning is professor at the Faculty of Law, University of Bergen, and was a member of the law committee that submitted this report. Georg Fredrik Rieber-Mohn was leader of the law committee, and is a former Supreme Court Justice and former Prosecutor-General of Norway.

1 In this article, Criminal incapacity will be used as the more general notion, including also criminal insanity. The Norwegian rules of criminal incapacity that are detailed further down include incapacity on the grounds of young age, unconsciousness, and insanity. Readers should be advised that this may differ from American or English concepts of criminal incapacity.

This is an Open-access article distributed under the terms of the Creative Commons Attribution 3.0 Unported License (http://creativecommons.org/licenses/ by/3.0/), permitting all use, distribution, and reproduction in any medium, provided the original work is properly cited. 
To investigate the need for legislative change regarding these issues, a committee was appointed by the government by way of royal resolution on 25 January $2013 .^{2}$ The committee presented its recommendation on 28 october 2014 in the report NOU 2014:10: Criminal capacity, expert knowledge, and the protection of society (Skyldevne, sakkyndighet og samfunnsvern). ${ }^{3}$

As a result of the many issues raised by the 22 July case, the committee received multifaceted competence, with representatives from the law, medicine and psychology, but also specialists in philosophy and ethics. This composition has also led to the committee examining the fundamental issues of criminal insanity in a deeper and more multifaceted manner than what has been done in previous reports on the topic in Norway. ${ }^{4}$

As a basis to understand the committee's work, it must be emphasised that the terrorist attacks on 22 July were the unavoidable backdrop for the committee. The experiences from the subsequent court case have influenced the committee's discussions in various ways. Generally the case was significant, as it cannot be ruled out that this type of tragedy, or cases that come near, can occur again. To a certain extent have existing rules not been able to apprehend such extreme cases as the 22 July case. The committee has nevertheless taken the principled position that the 22 July case, with its extreme character, ought not to have a decisive effect on the formulation of rules which will usually be applied in much less serious cases. The challenge for the committee has therefore been to avoid that the 22 July case would turn into a guiding reference for the typical application of rules on criminal insanity and related issues, while at the same time ensuring that these rules can also function in such cases.

\section{The central aspects of the mandate}

The committee's mandate was extensive. The committee was requested to undertake a broad assessment of the rules on criminal insanity in section 44 of the Penal Code, with particular emphasis on the provision concerning psychosis. The fundamental question put to the committee was to which extent persons with serious mental disorders can be held criminally responsible for their actions. Attention was also to be paid to criminal

2 The committee was led by Georg Fredrik Rieber-Mohn and included 11 members.

3 The report is public and can be accessed in Norwegian on: https://www.regjeringen.no/nb/dokumenter/NOU-2014-10/ $\operatorname{id} 2008986 /$ ?docId=NOU201420140010000DDDEPIS\&q=\&navchap $=1 \& \mathrm{ch}=2$ [Last accessed 06/07/2015].

$4 \quad$ See NOU 1974:17: Strafferettslig utilregnelighet og strafferettslige særeaksjoner; NOU 1990:5: Strafferettslige utilregnelighets- regler og særreaksjoner, straffelovkommisjonens delutredning IV. 
incapacity due to unconsciousness or mental retardation of high degree that are also regulated in section $44 .^{5}$

The committee was also requested to carry out a wide assessment of the role of experts in criminal cases where there is doubt on the perpetrator's criminal capacity, as well as to consider how society should be safeguarded when the defendant is insane and absolved from criminal responsibility.

In its report, the committee chose to break down its conclusions in three main topics, that are reflected in the report's title 'Criminal capacity, expert knowledge and the protection of society.' These are:

1. Criminal Capacity: Whether the Penal Code should contain rules on criminal insanity, and if so how these should be formulated;

2. Expert Knowledge: Which role experts should have in criminal cases that raise issues of criminal insanity; and

3. The Protection of Society: How society should protect itself from criminally insane persons who can be dangerous for the public at large, with a particular focus on the need for special criminal sanctions.

In the following an overview will be given of the legislative changes proposed by the committee in its report, along with the justifications for each of these. The overview is structured following the report's main topics as outlined above, and the committee's mandate will be detailed for each of these issues to the extent necessary.

The report was presented with only few dissenting or separate statements. Most of these dissenting and separate statements are related to issues of a more technical nature, where there was agreement in substance, but where different views were held on the configuration and formulation of the Penal Code. In this summary, only dissenting statements of a more substantial nature will be mentioned.

\section{Criminal capacity}

\subsection{Existing rules on criminal insanity}

The current Penal Code specifies in sections 44 and 46 the circumstances which indicate a lack of criminal capacity and exoneration from criminal responsibility. Section 44 
determines that the perpetrator is absolved of criminal responsibility if they were 'psychotic', 'unconscious', or 'mentally retarded to a high degree' at the time of the offence. ${ }^{6}$

The word 'psychotic' refers to the equivalent medical term, but the provision requires that the psychosis must be discernible at the time of the offence through obvious symptoms. A person that suffers from psychosis, but is under medication - and thus not (actively) psychotic - at the time of the offence, is therefore not included in the provision. The word 'unconscious' refers to extremely rare cases where the perpetrator has acted without perceiving their surroundings whatsoever, often with a subsequent loss of memory. Such cases can for example occur when sleepwalking or during an epileptic seizure. The expression 'mentally retarded to a high degree' in section 44 exonerates offenders with seriously impaired intellectual capacity. Under section 46 are minors under 15 years of age free from criminal responsibility.

The various grounds for criminal incapacity are thus all defined by specifying a particular condition - young age, unconsciousness, mental retardation and psychosis - which, when established at the time of the offence, lead to unconditional exoneration from criminal responsibility. This type of provision has often been described as a medical or biological model, in contrast to the so-called mixed models which many states operate with. A provision based on a mixed principle encompasses not only criteria based on a specific condition, but also typically psychological criteria and/or causality criteria. Under such a rule, it is therefore not sufficient that a perpetrator is in a particular condition at the time of the offence, but it must also be assessed how that condition has impacted the commission of the offence.

The medical model has been under much discussion after 22nd July, particularly in relation to the criteria of 'psychosis' and the division of roles between experts and judges. Under existing rules, it is the court that has the ultimate say on whether one of the abovementioned conditions existed at the time of the offence, but in practice experts have through their reports and conclusions had considerable - and often decisive - influence on the result.

Under its mandate the committee was asked to pay particular attention to the provision regarding psychosis. The age of criminal responsibility was outside of the committee's remit. The central legislative changes proposed for the criminal insanity rules will be explained in the following.

6 An English version of the Penal Code is available at http://app.uio.no/ub/ujur/oversatte-lover/ cgi-bin/sok.cgi?type=LOV [Last accessed 06/07/2015]. 
Bergen Journal of Criminal Law and Criminal Justice $\bullet$ 1/2015

\subsection{The proposal for a new rule in section 44 of the Penal Code}

The report proposes a new formulation of the rule on exemption from criminal responsibility on the grounds of insanity. The proposal preserves the medical model, though in a considerably watered-down form, and is as follows:

A person whom the court deems to have been psychotic at the time of committing the act, or in a condition which, due to reduced functioning, disordered thinking, or otherwise to the inability to comprehend their relationship with their surroundings, must be equated with psychosis, is free from criminal responsibility. The same applies to a person who acted under a severe disorder of consciousness.'

The basis for the committee's deliberations was the justification for punishment in general. In line with the justifications for punishment which Norwegian criminal law places particular emphasis on, criminal responsibility presupposes that the perpetrator has had a choice of action and can be blamed for the choice taken. In other words, the fundamental principle of guilt is central: only those that could and should have acted differently, and therefore can be blamed, should be held responsible and punished.

Certain offenders must be deemed to be in such a confused and abnormal state of mind at the time of the offence that they should not be held accountable for their act. It would be profoundly unjust to hold these individuals responsible and to punish them. As such criminal law must encompass rules on criminal insanity.

Crime prevention is another purpose of criminal law which is often emphasised. With regards to this purpose, the committee has also taken the stance that there is no benefit from holding liable those that are in such a confused and abnormal state of mind. The criminal justice system's regulating effect on behaviour - that is, its ability to induce members of the public to obey the law through deterrence and the formation of norms is not weakened by absolving these persons of criminal responsibility.

When devising with rules on criminal incapacity on the grounds of mental illness, the prime challenge is to achieve accuracy, such that freedom from responsibility only applies to those persons that should be exempted under criminal law's moral justifications. Since criminal insanity is a legal and social construct, it will always be possible to argue that a rule includes too many or too few. The committee has nevertheless taken as an ethical premise that while it is unfortunate to absolve too many, it is far worse to convict offenders that cannot be blamed for their actions. With this as a background, the report thoroughly discusses whether the medical model should be kept as a rule for criminal incapacity.

It first seemed judicious for the committee to propose a rule based on a mixed principle, which wouldn't 'blindly' exonerate the offender who was suffering of a serious mental 
disorder at the time of the offence, but which in addition would require that this condition has had an impact on his actions. It might at first be reasonable to assume at such a rule would better pinpoint those who should not be held responsible. It would also distinguish more clearly between the role of the experts, which would be to clinically assess the offender's mental condition, and the court's task, which would be to determine the significance of this condition as an excuse from criminal responsibility in the actual case.

Nevertheless, the committee ultimately considered that great uncertainty and difficulties hover over a rule based on a mixed principle. There is no secure basis for the decisive assessment of whether a diagnosed mental disorder has had influence on the perpetrator's offence. It is to some extent contentious in psychiatry whether a psychosis can be 'partial' and therefore only affect parts of a person's mind. The dominant view has long been, and still is, that psychosis affects the mind in every respect. It would therefore be subject to great uncertainty to decide whether there exists a causal relationship between the mental condition and the criminal act itself, or whether the offender has understood the significance of their action. Faced with such difficult questions, judges would naturally enough seek help from experts, who are assumed to best understand the unstable mind. But when psychiatry does not have any empirical or unanimous basis to establish whether there is a causal link between a psychotic disorder and the actual offence, even experts would also be forced to rely on loose assumptions. It is therefore arduous to assume that the court's influence on the final result would be strengthened with such a provision.

It is also a fact that in several of the countries that have mixed rules on criminal insanity, these have been met with opposition and criticism. Legislative changes have also been put forward to bring rules in line with the medical principle, submitted for example by the committee examining reforms of the Penal Code in Denmark, but these have not been followed up by the legislature there.

The committee has ultimately reached the conclusion that accuracy is to best be achieved within the framework of a provision based on the medical principle. The committee has however also concluded that some modifications must be made in the law to avoid the problems associated with the current rule. In the provision which the committee recommends, it is made clear that only offenders which were 'psychotic' at the time of the offence with a pronounced intensity of psychotic symptoms should be exempted from criminal responsibility. This is the mental condition which has the most significant and confusing effect on the mind, and thus is best suited to distinguish those who should be held accountable, from those who should not due to mental illness.

In the committee's view, it would however be too narrow to strictly limit criminal insanity to offenders who satisfy the legal definition of psychosis. The committee has therefore advised that also other conditions which can be equated with psychosis should be covered by the provision. The justification for exonerating certain offenders with serious 
mental disorders from criminal responsibility has namely a broader scope than the legal definition of psychosis would indicate. The same justification is also relevant for certain individuals with serious mental disorders that cannot be diagnosed with psychosis, but who can nevertheless have disordered thinking, reduced functioning, or a distorted understanding of reality, to the same extent and intensity as a person that is 'psychotic.' By way of opening for an exemption from criminal liability also for the few such cases that can conceivably arise, it is hoped that some acutely inequitable convictions can be avoided. One avoids thereby also that the term 'psychotic' is 'stretched' to cover these atypical cases in order to reach a fair solution.

In its proposal for the second paragraph of section 44 , the committee replicates the current arrangement that exonerates offenders that were 'unconscious' or 'mentally retarded to a high degree' at the time of the offence. The last category is however supplemented with the phrase 'or similarly impaired.' The reason for this recommendation is that there are individuals that are not mentally retarded from birth, but who later in life become so impaired that they function, cognitively and in other regards, in a similarly diminished manner to people with high-degree mental retardation. This is particularly applicable when extensive brain damage is inflicted for example by accidents or by advanced dementia. There is no reason why these individuals should not be exonerated from criminal liability to the same extent as those born with mental retardation.

\subsection{The division of roles between experts and the court}

To clarify the division of roles between experts and the court has been an important issue in the committee's deliberations. The committee has taken the position that experts should limit their participation to the discipline they know and are educated in, and that the judge has a clear and independent responsibility to irrevocably decide whether the defendant should be convicted or acquitted.

Under the committee's proposal, the experts' task will be to assess the offender's state of mind exclusively on the basis of clinical and scientific evaluation and following the international classification system for mental disorders, which is currently ICD-10. The experts should in their statement reach a conclusion within this scientific system, but should not take position on whether the law's requirement of 'psychosis' (or equivalent) is fulfilled.

This is an important change from practice under current rules, where experts often also make statements and reach conclusions about the law's requirements. In those cases, the experts drift towards the law and engage in legal practice (by interpreting the Penal Code). 
The medical understanding of psychosis is in the committee's view nevertheless the most important aid for the court when it must determine whether the perpetrator was psychotic in a legal sense at the time of the offence. The most distinctive characteristics and typical symptoms of psychosis are also specified in the draft new section 44 paragraph 1.

It is however apparent from the provision's wording that it is the court's assessment which is decisive. It also follows that the legal requirement of psychosis will be narrower than the medical term. It is thus the court's task to determine on an independent basis whether the perpetrator's disturbed state of mind was of such a character, and was apparent with such severe symptoms, that they should not be made criminally liable. This legal determination will have a clear empirical basis in the symptoms observed, something that experts can help shed light on with their particular knowledge and methodological tools. But the experts do not have the prerequisites within their discipline to answer the decisive question, which at its core is of a legal nature: was the defendant at the time of the offence so mentally disturbed that they should not be held responsible? By drawing a clear distinction between the expert and legal assessments, it is accurate to say that the proposed provision is built on a somewhat modified medical principle.

\subsection{The standard of proof in the determination of criminal incapacity}

Under current law it is the perpetrator's criminal capacity at the time of the offence which much be proven by the prosecution. Which standard of proof applies to the determination of whether the defendant was 'psychotic' is however less clear.

The general standard of proof in criminal law is often formulated by stating that any reasonable doubt should benefit the defendant ('in dubio pro reo'). This implies that it is far from sufficient for conviction that the defendant's guilt is highly probable. Certain proof and a solid persuasion are necessary. This is the same standard of proof that is enshrined in the legal systems of most civilised nations, and it has its ethical roots in a desire to avoid that innocents are convicted.

The Norwegian Supreme Court has ruled that the general standard of proof applies to all preconditions to criminal responsibility. Our highest court has, on the other hand, also ruled that the same standard of proof cannot be demanded for the determination of whether the perpetrator was or not psychotic, and therefore criminally capable, as for whether the defendant actually has committed the offence. A standard of overwhelming probability is, however, not sufficient for the determination of criminal capacity. A clarification of these statements has not ensued in current jurisprudence.

The committee discusses thoroughly the standard of proof to apply in the determination of mental capacity. In this context a number of viewpoints that are expressed in the 
Oslo district court's judgement in the 22 July case $^{7}$ are commented - inter alia, that to be deemed criminally insane should work in the defendant's disfavour. The committee's conclusion is that there are no compelling arguments for having a different standard of proof when determining whether the defendant is criminally capable, than for the other preconditions for criminal responsibility. It seems deeply unjust to hold some mentally disordered persons responsible, and there is no ground to lower the threshold to prove guilt in this particular matter.

\subsection{Criminal insanity and self-induced intoxication}

Section 45 of the Penal Code specifies an exception to the exoneration from criminal responsibility under section 44 , when the defendant was unconscious at the time of the offence. Where unconsciousness was a consequence of self-induced intoxication, it does not exempt the defendant from criminal responsibility. In case law, this provision is also applied to cases of psychosis triggered by substance abuse. Full criminal responsibility under section 45 is engaged as soon as the intoxication was self-induced, and the question of whether the state of criminal insanity was self-induced is not relevant.

The committee recommends that section 45 be changed to the following:

A person who has brought upon themselves a condition such as provided in section 44, can be liable to a penalty. Such conditions that are an effect of self-induced intoxication shall not exclude punishment.'

The justifications which warrant exoneration from criminal responsibility for persons with serious mental disorders are not, in the committee's opinion, applicable to the same extent when the defendant has brought the actual condition upon themselves, well aware that it involves a risk for unacceptable, and perhaps aggressive and violent behaviour. To impose criminal responsibility for such risk-taking would, in addition, be assumed to have clear preventive effects and reduce the extent of risky behaviour.

The recommended provision is devised generally and will be applicable for psychosis and equivalent conditions, as well as for severe disorders of consciousness. A condition is self-induced when it is brought about wilfully or by negligence. A relevant example of reprehensible, self-induced psychotic attack can be when a patient ceases to take a prescribed medicine, which they know to be necessary to hold the illness in check. The patient will often also know that a resurgence of schizophrenic symptoms, for instance, can be dangerous for their surroundings. Naturally, a person who risks a severe disorder of consciousness due to drinking large quantities of alcohol or consuming hallucinogenic substances would fall in under the provision.

The judgment is available at https://lovdata.no/static/file/834/toslo-2011-188627-24e.pdf [Last accessed 06/07/2015]. 
The provision recommended by the committee shifts then the focus from self-induced intoxication to self-induced criminal incapacity. The recommendation is a clear departure from the current section 45 , under which it is sufficient for full criminal responsibility that the intoxication is self-induced, or in other words that the defendant has drunk an amount such that they must expect being intoxicated. The threshold applied in case law is quite low. The defendant is then fully liable for the offences they commit in a subsequent unconscious state - even when they have drunk a quantity of alcohol which is well within the range of what is generally considered acceptable in today's society. On this point, the committee finds the current section 45 to be highly inequitable.

The recommended provision is designed as a facultative rule of criminal responsibility, expressed such as the perpetrator 'can' be liable to punishment. The justification for this is that situations can occur where the defendant admittedly has brought upon themselves the condition which lead to criminal incapacity, but where subsequent offences should nevertheless not lead to criminal responsibility. The committee envisages here primarily exceptional cases where the behaviour cannot be considered as 'unlawful', because it is within the limits of what is considered generally acceptable. For example, a patient that refrains from taking their anti-psychotic medicine, after consultation with a doctor and as a step in their treatment, should not be liable for punishment when the unfortunate consequence is criminal insanity and the commission of a criminal offence.

The committee is unanimous that it would not, for the time being, be reasonable to repeal the current section 45 , which has contributed to the development of an effective criminal framework for offences committed under disorders of consciousness resulting from self-inflicted intoxication. The committee therefore recommends that section 45 be maintained alongside the new proposal. It is the committee's wish, however, that section 45 be phased out in case law. It is at the same time recommended that the current section 45 should be understood and practiced in such a way that consuming a quantity of alcohol generally accepted to be reasonable does not automatically trigger criminal responsibility.

\section{$4 \quad$ Expert Knowledge}

\subsection{The role of the experts under existing law}

The committee's deliberations on expert knowledge have been focused, in accordance with the mandate, on the role of psychiatry in criminal cases where there is a doubt about the perpetrator's criminal capacity. The expression 'forensic psychiatry' (Norwegian: 'rettspsykatri') covers in this context the service that expert psychiatrists and clinical psychologists, appointed by the court, perform for the criminal justice system in individual cases. This service aims first and foremost to ascertain whether the defendant has a men- 
tal illness that is so serious that it can lead to criminal insanity, and whether a criminally insane defendant constitutes a risk for the life or health of members of the public, such that a special sanction of compulsory mental health care is appropriate.

An evaluation of the role of experts in criminal cases implies a broad appraisal of the current criminal rules and practice. The Code of Criminal Procedure ${ }^{8}$ contains a range of different provisions which for example give the legal basis for the appointment of experts, the court's definition of their mandate and assignment, and the use of forced psychiatric examination. There are in addition a number of other relevant provisions, such as rules on the duty of confidentiality in the Mental Health Care Act. ${ }^{9}$ In relation to the control of the expert's assignment, the Norwegian Board of Forensic Medicine and its practice are also significant. The committee's deliberations on this point have in other words been considerable, and only the most central parts will be highlighted below.

The role of psychiatrists in court has regularly been criticised - from different angles. This criticism has been an important backdrop for the committee's discussions, in the sense that it has highlighted important points of controversy in current law and jurisprudence.

Firstly, criticism has been levelled towards the lack of clarity in the expert's role as the court's guide, and the tensions that this role entails. The expert's profession is usually associated with treatment of the sick, where the patient's interests are central. In contrast, as for the expert in a criminal case, the defendant is the object of an examination which will give the court the basis for reaching the correct decision about criminal insanity. The confidentiality and duty of secrecy that are applicable in the first role are in principle absent in the second.

It has also been the subject of frequent criticism that the experts are not sufficiently independent, and that they have connections with different instances which colour their judgment and conclusions. It has likewise been held that they can be too dependent on each other, for instance because they have worked closely together for many years. It has been claimed that such relations inhibit the independent judgement that each expert is required to deliver. In this context it has also been claimed that the external control of the expert's reports, which is primarily carried out by the Norwegian Board on Forensic Medicine, is insufficient.

Finally, the committee mentions the criticism that forensic psychiatric experts are given more influence in the outcome of the criminal case than can be justified by their discipline's findings. It is claimed that the courts endorses almost indiscriminately the view expressed by the experts and the conclusions they reach. In this regard, it is alleged that the courts are not sufficiently aware of the questions they should ask the experts, and that

8 'Straffeprosessloven', Act of 22 may 1981 nr. 25, lit. 'Criminal Procedure Act'.

9 'Psykisk helsevernloven', Act of 02 July 1999 nr. 62, lit. 'Mental Health Protection Act'. 
there is a lack of guidelines regulating how the experts' reports should be formed, and that the communication between the court and the experts is therefore unsatisfactory.

With these criticisms as a backdrop, the committee has recommended numerous minor changes. These will be highlighted below, with focus on the court's appointment of experts, the experts' execution of their assignment and the control that is carried out on their performance.

\subsection{Recommendations for changes}

\subsubsection{The appointment of experts}

According to its mandate, the committee had to consider how best to ensure that the prosecution only requests the appointment of experts in those cases where this is necessary. From a due process perspective, it is clearly more objectionable that experts not be appointed in cases where there are grounds to review the defendant's criminal capacity, than that experts might be appointed in too many cases.

The police and prosecution are engaged early on in criminal cases, and it is important that these institutions keep a watchful eye for possible signs of serious mental disorder in a suspect, and ensure that a preliminary psychiatric examination is performed when such signs are apparent. The committee finds it arduous to recommend legal amendments that would effectively ensure that the police and prosecution request expert assistance in the right cases, but does point towards several measures that may be implemented within the existing legal framework. It may in any case be judicious for the Code of Criminal Procedure's overarching provision on police investigation (Section 226) to be amended, with an additional reminder to the abovementioned institutions, that ascertaining the suspect's state of mind at the time of the offence is a part of the investigation's purpose.

The number of experts that are appointed is regulated by section 139 of the Code of Criminal Procedure. The provision determines that only one expert should be appointed, unless the court considers that the case requires two or more experts. In cases where there are doubts on the criminal capacity of the suspect the current practice is nevertheless to appoint two experts. The committee is of the opinion that the general rule should be the appointment of two experts in these cases. This consistently ensures a more thorough control of the quality of the assessment. When the experts act as intended and each have their autonomous and independent assessment of the defendant, notwithstanding mutual dialogue and exchanges of views, they supplement each other and contribute to the case being adequately clarified.

Section 139 of the Code of Criminal Procedure provides also for the court to appoint additional experts, beyond the two that are appointed in cases on criminal incapacity, 'when 
it finds it necessary'. It was this provision that the legal authority the Supreme Court's Appeal Committee relied on when it accepted that Oslo district court had appointed two new experts in the 22 July case, without either of the parties requesting it. The Appeal Committee ruled that when two experts had already been appointed at the request of the prosecution, the court was free to supplement them without a new motion being filed by the parties.

The committee has analysed the legal situation created by this decision. There were diverging opinions about whether the decision is judicious, and whether it is in harmony with fundamental principles of criminal procedure. The committee's deliberations on this point are thorough, but do not offer a clear conclusion. It is in the committee's opinion more advisable to leave the continued elucidation of this matter to the newly appointed legislative committee which will devise a new Code of Criminal Procedure.

\subsubsection{Competence requirements}

The minimum requirement to be appointed as a psychiatric expert is that the expert has completed its education as a doctor or psychologist. There is no requirement to have completed a speciality, and no obligation for the expert to be registered to use a protected title or equivalent. In practice, further professional training is nevertheless arranged for those wishing to serve as experts.

The committee makes no recommendation to change the basic educational curriculum to qualify as a doctor or psychologist, nor does it suggest changes in further education in the form of specialisation. The most reliable measure to ensure high quality in the work done by experts is, in the committee's opinion, to further professional training courses. The established courses should be maintained and allocated more resources. The content of the courses should nonetheless be adapted to the altered role experts will have if the committee's recommendation is adopted. As explained above, the experts will study the defendant's state of mind on the basis of clinical and medical assessments, and thus give the court the basis for ruling on whether the defendant was criminally insane. The experts will not conclude their report with a judgement of whether the defendant's state of mind satisfies the law's requirements.

Expert assignments should primarily be given to professionals who have completed the specialist training course. It should be a requirement that at least one of the experts has done so when two experts are appointed, which is currently usual in practice and would be the general rule under the committee's suggestion. When - exceptionally - only one expert is appointed, it should be a requirement that this expert has completed the specialist course. In the committee's view, it should also be a requirement that at least one of the experts appointed has up-to-date clinical experience within their discipline. 


\subsubsection{The experts'independence}

In order for the legal community and for society as a whole to have trust in the work of experts, they must appear - as well as be - autonomous and independent. In the current Code of Criminal Procedure, the threshold for disqualification of experts in general, and not only forensic psychiatrists, has, however, been formulated mildly: 'when it can be avoided,' a person should not be appointed as expert, who would be disqualified under the rules applicable to judges. And further: 'as a rule, there should not be appointed experts that are in a relation of dependency to each other.'

The committee is of the view that the law's rules on disqualification should be made more stringent and recommends the following provision: 'A person that would be disqualified as a judge in the case, cannot be appointed as expert.'

Likewise, the provision on independence should be considerably stricter. A central purpose of appointing two experts is that they should work independently. The committee is of the opinion that experts that have a close relationship to one another, whether that is a friendship or a matter of having served as experts together for a number of years, can give cause for concern. It isn't enough that the experts considers themselves to be independent, or that they actually are - the court and society at large must also perceive that it is so.

On the other hand, close collaborators cannot be automatically excluded as experts. Many will be able to act professionally and with the distance and independence that are necessary as an expert. Such an automatic exclusion, in a small country like Norway could create considerable problems in appointing qualified experts.

With this balancing act in mind, the committee recommends that the provision be made stricter along the following lines: 'The appointment should be avoided where connections to parties in the case or other experts, or other circumstances, may raise doubts as to the expert's independence or impartiality.'

\subsubsection{Mandate and statements}

Section 142a of the Code of Criminal Procedure provides that for all services of experts ordered by the courts, a written mandate should be provided the expert by the court. The formulation of the mandate is important for the expert themselves and their work, and particularly as a way to ensure the best possible clarification of the case. The provision applies similarly when the prosecution employs an expert at the investigative stage, with the difference that it is then the prosecution service that determines the mandate. This provision also gives the Government competence to enact further regulations regarding the composition of the mandate. This delegation power has not been used. 
The committee was asked to evaluate whether further regulations should be laid down to regulate the composition of mandates for experts, and additionally to make a recommendation as to which requirements that should apply to the content of experts' concluding statements.

For some years now, the practice of the prosecution service has been to use a standard mandate, composed in collaboration between the Prosecutor General ${ }^{10}$ and the Norwegian Board of Forensic Medicine. This is also used by the court when appointing experts. The matter of concern is whether this practice is satisfactory, or whether further regulation is necessary. In any case, it would be necessary to adjust the standard mandate to reflect the more limited role of experts that the committee recommends, particularly in respect with the fact that experts no longer should determine whether the law's requirements for criminal incapacity has been fulfilled, but rather restrict themselves to scientific and medical assessments.

The committee has concluded that further regulations should be enacted providing for a minimum standard for the composition of the mandate. This standard should prevent oversights and undesired variations in the experts' work. The standard mandate should not be regulated in such detail that it would impede a concrete adjustment in the various cases that arise, with their peculiarities. The committee is also presenting a draft regulation regarding the guidelines to apply in the composition of the mandate for expert assignments in general, and a draft standard mandate for experts in cases pertaining to criminal insanity and related issues.

For criminal rulings to be as correct as possible, it is also essential that the courts understand all evidence in the case. Uncertainties and possible errors must be brought to light. Expert statements are written by doctors or psychologists. Reviewing them therefore requires specialist knowledge, which neither the prosecution service nor the courts possess. Both prosecutors and judges are often encouraged to rely on the experts' assessments. These statements are thus granted substantial weight in their own right, and are often characterised as authoritative evidence.

But the legal profession is not entirely without recourse to control these reports, when asking the right questions. It is in that way possible to examine whether the factual basis for the expert's assessment is satisfactory. It is also to a certain extent possible to control whether there is a logical correlation between the examination's factual foundations and the conclusions drawn.

An important requirement to ensure a satisfactory level of control by the court is in any case that the experts must expressly convey any uncertainty they may have, whether that is in relation to the facts the statement is built on, or to the medical diagnosis they have 
reached. Another important requirement is that the experts must be aware of their role to pass on knowledge, and that they express themselves using a terminology that enables legal professionals in court to understand what is said.

It is also decisive that legal professionals have a certain grasp of the experts' discipline, if they are to review the statements made. The assessment of evidence, and psychiatry, are not part of the university curriculum for legal studies. In addition, most of Norway's 350 professional judges will rarely, if ever, be assigned cases where criminal incapacity is an issue. The committee cannot envisage any easy solution to remedy this lack of competence. It is of the opinion that it is most sensible for the courts, the police, and the prosecution service, to ensure themselves that measures to improve competence levels are implemented, given that only few such cases arise per year.

\subsubsection{The Norwegian Board of Forensic Medicine}

The Norwegian Board of Forensic Medicine has as its overarching mission to carry out control and review within all subdisciplines of forensic medicine, and is divided in subgroups in charge of a specific area of expertise. The forensic psychiatry group consists of six psychiatrists and three psychologists. The most significant external control of experts' work is thus performed in the commission, by specialists who presumably possess at least equal competence to the experts. Apart from control in individual criminal cases, the Board has a more general supervisory function. The committee was asked to assess several aspects of the commission's activities.

Members of the Board are currently appointed by the government, with secretarial support from the Civil Affairs Authority. ${ }^{11}$ This gives a satisfactory guarantee for the independence of the Board. It is decisive for the commission's legitimacy that its leaders and members have high scientific and specialist competance. Not only does this ensure high quality when performing control in individual cases, it also provides a sound basis for the Board to contribute to scientific development within the discipline and ensure a consistent practice among the experts that regularly participate in the criminal justice system. As a result of the sharp distinction the committee is advocating between scientific/medical support and the legal assessment undertaken by the court, the Board of Forensic Medicine's supervisory function will be defined more clearly, and should be easier to relate to.

To ensure a high level of competence in the Board, the committee suggests that a professional appoinment committee be established to make recommendations when new members of the Board's subgroup for forensic psychiatry are to be appointed. At least one of the appointment committee's members should be a university professor in psychiatry or psychology. This would strengthen the Board's independence. The committee recom- 
mends also that the administration of the Board be supplemented by a legal professional that would have the important task of clarifying the distinction between medical and legal assessments in criminal cases..

The Board's primary task is to inspect and control the statements that court-appointed experts give to the court, a copy of which they are obliged to send to the Board. The committee recommends also that experts who wish to make a statement concerning psychiatric issues of relevance in a criminal case, but who are not appointed by the court, should be required to (also) submit their statement to the court in writing, a copy of which should be sent to the commission for inspection.

Three of the Board's members participate in this inspection. In principle, the Board has the authority to review all aspects of the experts' work, including the factual basis it is built on. In practice, the inspection is limited to a study of the written statement, where the commission ensures first and foremost that there is a logical correlation between the examination's factual foundations and the conclusions drawn, besides ensuring that the statement is not based on conflicting assumptions. The committee recommends that this procedure be maintained, with minor changes. In particular should the Board's conclusions reflect to a clearer extent the exact inspection that has been carried out. The committee has drafted new formulations which may be used by the commission when writing inspection conclusions.

\section{The protection of Society}

\subsection{Current rules on special sanctions for insane perpetrators}

The provisions on criminal insanity entail that an offender can be exonerated from criminal responsibility. A criminally insane offender is without criminal capacity, and therefore is innocent, both in principle and in fact.

Even so, it can be necessary to intervene with force towards such an offender, in order to protect the public from new crimes. Under current criminal law, provisions are made in this regard to use special sanctions, which are to ensure that an offender that is presumed to be dangerous does not reoffend. This is achieved by carrying out coercive measures as well as medical treatment for their mental disorder.

These measures are regulated by sections 39 and 39a of the Penal Code, which open for the use of special sanctions, respectively to transfer [the offender] to compulsory mental care and to transfer to compulsory care. The former is intended for offenders that are criminally incapable due to psychosis, to severe disorders of consciousness, or equivalent, while the latter is intended for the intellectually disabled. The law's requirements are the same for both categories. In order to impose these sanctions, it is required that 
1) a serious crime involving a violation of integrity has been committed (the provision itemises certain crimes that match this description), and there is an imminent risk that a new crime be committed which would set other persons' life or health at risk or encroach on their freedom, or that 2) a less serious crime of the same type has been committed, and the danger for new such crimes is particularly imminent.

There is thus a high threshold under Norwegian law in order to apply these special criminal sanctions. This is justified by the view that criminal law should not, in principle, impose a reaction upon offenders who are without guilt. As a result, other statutory provisions, giving authority to impose coercive measures within health and social legislation, play a major role in ensuring that the appropriate measures are imposed on those offenders. The most important provision is to be found in the Mental Health Care Act. But those provisions do not, to the same degree as provisions in criminal law, take into account the potential dangerousness of an offender.

\subsection{Recommendations for changes in the provisions regulating special sanctions}

The committee finds it necessary to maintain a system of special criminal sanctions. Society has a legitimate interest in protecting itself from the danger that some criminally incapable offenders represent. Nevertheless, the committee is of the opinion that such preventive measures as special sanctions are at odds with our culture's strong emphasis on individuals' freedom. The threshold for the deprivation of liberty that special sanctions entail should therefore be high. The committee wishes to underline that such an encroachment on personal freedom is only justified when it is suitable, when it is necessary, and when it is proportional to the benefits it seeks to protect.

The committee is of the view that there are sensible reasons to allow for verdicts of special sanctions to protect the life, health and freedom of members of the public, as the basic legal values that sections 39 and 39 a is designed to safeguard. The committee would nevertheless recommend changing these provisions so that they become applicable to a few more cases than they currently do. The committee has studied some cases where relatively serious crimes had been committed, which involved violations of personal integrity, and where there was considered to be an important risk of new and serious criminality, but where the law's strict requirements regarding the crimes committed was nonetheless not deemed to be met. In the committee's view, special sanctions should be applicable to such cases, not least because the possibilities for coercive treatment under the Mental Health Care Act offer insufficient protection.

More concretely, the committee considers it a good starting point that the provision is devised with a high threshold for the level of danger required to trigger its application. However, in the committee's view, the present law attaches too much importance to whether certain crimes have been committed, and the committee wishes that attention 
rather should be directed to the danger to important legal values. The level of danger required should be higher when the value at stake is of relatively lower importance, but should be markedly lower when a particularly significant value, such as life, is threatened, for example where there is a risk of murder. In that way, the danger assessment performed by the court would become relative to a certain extent, depending on the importance of the threatened value.

Furthermore, the committee considers that the provision's first requirement, regarding the offence which is required to have taken place, should be designed to reflect the risk posed by the perpetrator to the life, health, and freedom of others, but should not be formulated overly strictly. Offenders that represent a real risk for important values should fall under the provision. The minimum requirement must be that an action is taken which puts the life, health or freedom of others at risk. The committee recommends removing the current requirement that a 'serious' violation has been committed.

\subsection{General recommendations for the implementation of the sanctions}

The committee takes for granted that the mental health service as a whole should have the responsibility for placing and treating offenders that have been imposed a special criminal sanction. The offender should be treated with the overarching principle that they are absolved of criminal responsibility, and thus cannot be blamed for the misconduct that is the basis for the sanction. This also means that they should not be subjected to other limitations of their freedom, than those that are strictly necessary for the protection of others.

Within these limitations, any stay at an institution should be filled with positive and meaningful content. The institutions that look after this group must be adequately staffed by professionals and receive the resources they need. It should generally be ensured that special criminal sanctions of compulsory care are something completely different than punishment, and that punitive elements are not present when the sanctions are carried out. In the committee's opinion, this is essential out of consideration for the Norwegian constitution, as well as Norway's human rights obligations. The committee therefore recommends a new provision in the Mental Health Care Act's chapter on the implementation of special criminal sanctions. The provision would entail that persons transferred to compulsory mental health care may not be subjected to further limitations and encroachments to their freedom than is necessary for their treatment and for the protection of the patient themselves, other patients, and for society as a whole. Within these limitations, everything should be done to ensure these patients live as normal a life as possible. It is recommended that this provision also be made applicable to the intellectually disabled who are in compulsory care. 


\subsection{Commitment in closed institutions}

Under current rules, the court has neither influence on the actual execution of the special criminal sanction, nor in fact on the issue of how the protection of the public should be guaranteed during that time. The only requirement that follows from current rules is that any person who is transferred to compulsory mental health care must be placed in an institution as an in-patient for the first three weeks. ${ }^{12}$ The committee has deliberated whether this procedure is sufficient to safeguard the public, given that medical staff are -after the initial three-weeks-period- at liberty to choose less restrictive forms of treatment.

It is undeniable that for some of the offenders who are imposed compulsory mental health care, there might be a danger to the public that is related to an illness, or a state of mind, which there is little hope to cure in the foreseeable future. Members of this group can be detected with a high degree of reliability. In order to ensure a stabile treatment for this group of patients, and to protect the public, the committee has reached the conclusion that it should be possible for the court to specify in its verdict that this particular type of offenders is committed round-the-clock into a closed psychiatric institution until further notice. The committee recommends that the conditions for such a commitment is that there are no prospects of any speedy or substantial improvement in the offender's health of mind, and that the protection of the public, or other significant interests, requires it. This entails that the court sets a frame for the work of the attending physician, which also means that medical staff will to a much lower extent have to constantly reassess the danger represented by their patient at any one time. Discharge from a closed institution could in those cases only be ordered by the prosecution service, or if the prosecution is opposed to the discharge, by the court upon request from the offender.

\subsection{Duration of the commitment}

As is currently the case, special criminal sanctions would under the committee's recommendations be of an indeterminate duration. The prosecution service can decide to lift the sanction. Otherwise, the termination of the sanction must be requested to the court at the behest of offender themselves or their next of kin, though this motion may only be lodged from one year after the verdict or any possible appeals have become final. If such a motion is unsuccessful, a new motion can be lodged one year after the original motion or any successive appeal have become final.

12 Act No. 62 of 2 July 1999 relating to the provision and implementation of mental health care (the Mental Health Care Act), available in English at http://app.uio.no/ub/ujur/oversatte-lover/data/ lov-19990702-062-eng.pdf. 
The committee was asked to consider whether the seriousness of the crime committed should have any implication for the length of the intervals at which motions can be lodged, but refuses to entertain such a thought. This would most worryingly result in special criminal sanctions taking on more markedly the character of a punishment.

Since it is recommended that the court be given the power to decide that the offender should be consigned to a closed institution round-the-clock, the question will arise of how long such a commitment should be. The committee considers that the prosecution service should be able to lift the commitment when it is no longer needed, for example because the circumstances are altered radically because the offender suffers from a serious physical illness. The offender or their next-of-kin may also lodge a request to the court to lift the commitment a year after it was ordered, and then once a year.

The committee has also discussed whether there should be access to impose a minimum duration for this type of round-the-clock commitments, with the consequence that the offender and their next-of-kin cannot request that the sanction be lifted before the minimum duration is over. This question may be relevant in a few cases where criminally incapable offenders represent a particularly high risk to the public.

In considering the need for a minimum duration, the committee was divided. The majority found no reason to introduce a minimum duration. A lot can change after the offender is committed to a closed institution. They can for example have sustained injuries or illness, which physically prevent them from reoffending. It is also doubtful how much is to be gained by depriving the offender of the fundamental right to judicial review of the forced commitment. As long as they are regarded as dangerous and remain in closed institution, the possibility of judicial reviews at one-year intervals cannot be too demanding.

The minority is of the opinion that it is necessary to give the court possibility to stipulate a minimum duration for forced commitment, of up to three years. This is particularly justified out of consideration for the calm necessary in the programme of treatment, but also to a certain extent by the public's expectation for a more durable protection from this group of offenders. It is also economical to avoid court proceedings in cases where the result is a certainty. If changes occur in the offender's situation, for example because the offender contracts a serious illness that makes forced commitment unnecessary, there is a sufficient guarantee in the fact that the prosecution service can lift the sanction at any time.

\subsection{Transfer to the correctional services}

The current section 5-6 of the Mental Health Care Act contains a restricted possibility to transfer an offender who has been imposed a compulsory mental health care measure 
to a facility managed by the correctional services. That means that a person who was understood as criminally insane, and therefore not met with imprisonment, may in some cases be transferred to prison. Such transfer may only take place when the person is no longer psychotic and criminally insane, but still particularly dangerous for the public.

The committee is unanimous in considering it as a matter of principle both unfortunate and unsatisfactory that persons that are not criminally responsible should be sent to prison. However the committee is divided with regards to the conclusions that should be drawn from this ethical standpoint.

The majority is of the opinion that a transfer procedure is necessary in extraordinary cases, and that this possibility should remain until the mental health services have facilities and resources to enable them to care for difficult patients in a satisfactory manner. The need for a transfer to the correctional services is present when the mental health services have nothing to offer the offender, and where the costs and difficulties of retaining the patient become disproportionately high.

The majority is recommending additional precisions to section 5-6 of the Mental Health Care Act, which would further restrict and clarify the requirements for a transfer to take place. It must be a precondition that a specific treatment programme for the offender is already established under the auspices of the correctional services, which contains no punitive element and which is clearly separate from what is offered to other inmates. Such a restricted transfer procedure would not be in breach of constitutional or international obligations.

A minority is however of the view that the transfer procedure should be abolished. In the opinion of the minority, it is highly problematic that section 5-6 gives the possibility to place persons with severe mental illness, who cannot be blamed for their crimes, in prison. The type of prison confinement which would inevitably be the result of such a transfer would be arduous to distinguish from criminal incarceration, with all its unpleasantness. This would be the case regardless of how 'nicely' the law may dictate how the transferee is to be treated. Section 5-6 of the Mental Health Care Act should consequently be repealed, in the minority's opinion.

\section{Postscript: The status of the legislative process}

The legislative process has continued after the proposal. The proposal has been the object of a consultation round to the government and many different institutions and organisations have replied. ${ }^{13}$ The reactions to the proposals have been diverse. Surprisingly

13 See https://www.regjeringen.no/nb/dokumenter/Horing--Tilregnelighetsutvalgets-utredningNOU-2014-10-Skyldevne-sakkyndighet-og-samfunnsvern/id2341869/

[Last accessed 06/07/2015]. 
many of the responding instances have been positive towards keeping a medical model for the rule on criminal insanity, and many of those have welcomed the committee's amendment recommendations. Many have also been positive towards the proposal to enforce a stricter division between forensic psychiatric experts and the court, as well as to the recommended changes to rules on special criminal sanctions.

But there have also been critical remarks. Several of the responding instances expressed their wish to see the medical model abolished, and replaced by a mixed model that would require that the specific effect of the mental disorder on the commission of the criminal offence also be evaluated. Several instances were particularly critical to the choice to keep the term 'psychosis' due to the stigmatising effect the use of this term might have on those with mental disorders. And some has also been critical towards the changes regarding the role of the experts and the rules on special criminal sanctions.

In the end, these different reactions reflect the difficulty in regulating criminal insanity in a way that is both understood as principally adequate and legally practical. It also reflects that there are many different opinions in society when it comes to matters of crime, criminal responsibility and criminal sanctions. In this context, it will be interesting to see what legal changes, if any, this proposal will eventually result in. The next step is, in that case, a Draft resolution from the government that will form the basis for enactment of new legislation in parliament (Stortinget). 